\title{
Fantasia e metaficcionalidade nos romances de Zamonien de Walter Moers
}

\author{
[Fantasy and metafictionality in Walter Moers' Zamonien Novels]
}

Laura Alves do Prado ${ }^{1}$

\begin{abstract}
Walter Moers is one of the most important authors of contemporary Fantastic Literature in German. Since his first novel, in 1999, the author turned into a bestselling writer. His last six novels all share a common element: the fictive continent of "Zamonien", a fantastic world created by Moers. In this invented world the reader finds a lot of adventures, battles, journeys, conquests, mysteries, fights, dangers, unusual creatures and unknown places. If on one hand, the fantastic works of Moers respond to conventions of the Fantasy genre, on the other hand, they offer a new literary proposal, which breaks some conventions of this genre. This is particularly the case of the metafictional elements, which are very frequent in his novels. This paper intends to introduce a novel of Walter Moers, Die Stadt der träumenden Bücher (2004), and to discuss its constitutive elements, which classify the book as a work in the Fantasy genre, emphasizing especially the metafictional aspects .
\end{abstract}

Key-words: Walter Moers; fantastic literature; fantasy; metafictionality; intertextuality

Resumo: Walter Moers é um dos grandes autores da vertente fantástica dentro da literatura alemã atual. Desde a publicação de seu primeiro romance, em 1999, o escritor consagrou-se como autor de best-sellers. Nos seis romances publicados até a presente data tem-se um elemento comum, que serve de fio condutor às obras: o continente fictício de "Zamonien", um mundo maravilhoso criado por Moers. Esse mundo inventado é palco para inúmeras aventuras, lutas, jornadas, conquistas, mistérios, disputas, perigos, criaturas inusitadas e cenários desconhecidos. Se, por um lado, as obras fantásticas de Moers estão de acordo com as convenções do gênero da Fantasy; por outro, elas trazem consigo uma proposta literária inovadora, que rompe com algumas convenções desse gênero. É o caso da metaficcionalidade, presente de forma marcante em seus romances. Pretende-se nesse trabalho apresentar brevemente um romance de Walter Moers, Die Stadt der träumenden Bücher (2004), discorrer sobre os elementos constitutivos que inserem a obra no gênero da Fantasy e, por fim, aprofundar-se nos aspectos da metaficcionalidade encontrados na obra em questão.

Palavras-chave: Walter Moers; literatura fantástica; Fantasy; metaficcionalidade; intertextualidade

\footnotetext{
${ }^{1}$ Mestranda do programa de pós-graduação em Língua e Literatura alemã na Faculdade de Filosofia, Letras e Ciências Humanas da Universidade de São Paulo.E-Mail: lauraprado@usp.br
} 


\section{Introdução}

Walter Moers tornou-se inicialmente conhecido como autor e ilustrador de quadrinhos. Desde 1984, publicou diversas obras do gênero e consagrou-se por suas personagens marcantes e provocadoras, pelo tom crítico, irônico e satírico de seus quadrinhos e, especialmente, pelo humor negro com que ele tematiza tabus e tudo o que é considerado politicamente correto. Tome-se como exemplo, alguns de seus protagonistas: Kleines Arschloch é um garoto míope e astuto que provoca os adultos com perguntas indelicadas; Der alte Sack, um idoso em uma cadeira de rodas que faz comentários sarcásticos sobre tudo e todos ao seu redor; e, por fim, Adolf, die Nazi-Sau, um quadrinho que ridiculariza Adolf Hitler nas mais variadas situações, trazendo-o aos dias de hoje.

Em 1999, Moers estreou no mercado editorial como autor de romances e ilustrador de suas obras com Die 131/2 Leben des Käpt'n Blaubär, que ficou na lista de best-sellers da revista Der Spiegel durante 30 semanas. À época, esse texto foi considerado o segundo romance de ficção mais vendido, apenas atrás de Mein Jahrhundert de Günter Grass, que ocupou o primeiro lugar. Die 131/2 Leben des Käpt'n Blaubär inaugura uma série de best-sellers que apresentam um mesmo fio condutor: o continente fictício de "Zamonien”, um lugar fantástico, palco para inúmeras aventuras dos muitos personagens inventados por Moers.

Die Stadt der träumenden Bücher, publicado em 2004, é considerado o grande sucesso de Moers e sua melhor obra. Ele ficou 21 semanas na lista dos 15 livros de ficção mais vendidos e rendeu ao autor em nove de setembro de 2005 o PhantastikPreis der Stadt Wetzlar (LEMBKE 2011: 27-32). Nesse romance, Moers trata de forma satírica do livro, da literatura e do mercado editorial a partir de diferentes instâncias: poetas, editores, agentes, vendedores, donos de livrarias, críticos literários e leitores. Trata-se de um mundo fictício que gira em torno do livro e da leitura, no qual se estabelece uma tensão entre arte e indústria cultural (cf. BUNIA 2010: 190).

A trama de Die Stadt der träumenden Bücher desenvolve-se a partir da missão recebida pelo protagonista, Hildegunst von Mythenmetz, um "Lindwurm" aprendiz de escritor. Ele deve partir em busca do autor de um misterioso manuscrito, cujas qualidades literárias são tão excepcionais que despertam as maiores e mais intensas 
emoções naqueles que o leem. Evoca-se aqui claramente a imagem do gênio poético romântico e de sua obra universal. A jornada de Mythenmetz o conduz a "Buchhaim", a cidade dos livros sonhadores, onde tudo se dá a partir da literatura e dos livros:

\begin{abstract}
Buchhaim verfügt über fünftausend amtlich registrierte Antiquariate und schätzungsweise tausend halblegale Bücherstuben, in denen neben Büchern alkoholische Getränke, Tabak und berauschende Kräuter und Essenzen angeboten wurden, deren Genuß angeblich die Lesefreude und die Konzentration steigerten. Es gab eine kaum meßbare Zahl von fliegenden Händlern, die auf rollenden Regalen, in Bollerwagen, Umhängetaschen und Schubkarren Druckwerk in jeder denkbaren Form feilboten. Im Buchhaim existierten über sechshundert Verlage, fünfundfünfzig Druckereien, ein Dutzend Papiermühlen und eine ständig wachsende Anzahl von Werkstätten, die sich mit der Herstellung von bleiernen Druckbuchstaben und Druckschwärze beschäftigten. Da waren Läden, die Tausende von verschiedenen Lesezeichen und Exlibris anboten, Steinmetze, die sich auf Buchstützen spezialisiert hatten, Schreinereien und Möbelgeschäfte voller Lesepulte und Bücherregale. Es gab Optiker, die Lesebrillen und Handlupen fertigten, und an jeder Ecke war ein Kaffeeausschank, meist mit offenem Kamin und Dichterlesungen, rund um die Uhr. (MOERS 2008: 31)
\end{abstract}

Em "Buchhaim" encontra-se de tudo um pouco: agentes literários ávidos para encontrar um possível best-seller, editores atentos e cuidadosos, livreiros oportunistas, editores manipuladores que controlam o mercado literário, leitores mais ou menos experientes em busca de novas obras literárias, escritores consagrados e também poetas idealistas que não conseguem publicar suas obras e acabam por pedir esmolas dentro de pequenas covas no "Friedhof der Vergessenen Dichter". Nessa cidade fantástica pode-se encontrar todo e qualquer tipo de livro: clássicos universais, romances de aventura, livros infanto-juvenis, livros baratos e caros, raridades, livros perigosos, proibidos ou envenenados e, especialmente livros sonhadores, que anseiam pelo momento em que serão lidos por algum leitor. Em "Buchhaim” até mesmo a relação dinâmica autor-obraleitor é realizada de maneira concreta.

Depois de viver muitas aventuras, superar dificuldades e lidar com os maiores perigos, Mythenmetz encerra sua jornada cumprindo a missão que lhe foi designada e encontra o autor do misterioso manuscrito. Todavia, o "Lindwurm" consegue também cumprir com sua outra missão, a de se tornar um grande poeta. Como comprovação da formação desse grande escritor, o leitor tem o próprio romance em suas mãos, pois quem se apresenta como autor de Die Stadt der träumenden Bücher é Mythenmetz. O 
livro retrata, portanto, as memórias do protagonista-autor daqueles acontecimentos que o levaram a se tornar um escritor. Walter Moers é, por outro lado, apresentado como tradutor das memórias do dragão-escritor do idioma "zamonisch" para a língua alemã.

A problematização da relação triangular entre autor, narrador e personagem instaura uma ficção autoral no romance. Ao afirmar que o $\mathrm{N}=\mathrm{P}$, ou seja, que o narrador Mythenmetz é também personagem, mas que $\mathrm{A} \neq \mathrm{N}$, temos uma ficção homodiegética (Cf. Genette 1992: 83). Para tanto, é imprescindível acreditar que Walter Moers é o autor de Die Stadt der träumenden Bücher, e não seu mero tradutor, como indicado na contracapa do livro. Todavia, o romance apresenta-se ao leitor como uma autobiografia $(\mathrm{A}=\mathrm{N}=\mathrm{P})$ de Mythenmetz, atribuindo a Moers apenas o papel de tradutor dessa obra. A ficção autoral é bastante ressaltada e intensificada ao se notar a insistência na não identidade entre Moers e Mythenmetz e na não autoria de Moers no peritexto ${ }^{2}$, e, especialmente, em epitextos ${ }^{3}$.

Com relação ao peritexto, a ficção autoral não é apresentada somente na contracapa do romance, mas também no "posfácio do tradutor" e nos agradecimentos finais. No posfácio, por exemplo, Moers dirige-se aos leitores de Die Stadt der träumenden Bücher, pedindo que eles entrem em contato através de um endereço eletrônico, opinando a respeito de qual obra de Hildegunst von Mythenmetz deveria ser a próxima a ser traduzida do "zamonisch" para a língua alemã .

A ficção autoral foi amplamente tematizada através de epitextos veiculados em discursos consensualmente factuais (BUNIA 2010: 192). Muitos exemplos desse fenômeno podem ser encontrados ao se realizar uma busca em artigos relacionados ao assunto na mídia impressa. Um caso bastante particular é a entrevista com Walter Moers

\footnotetext{
${ }^{2}$ Entende-se por "peritexto" tudo o que está tipograficamente separado do texto principal, mas que se mantém ligado materialmente ao livro (cf. GENETTE 1992).

3 "Epitextos" compreendem todos os textos que falam a respeito do texto de referência (no caso desse artigo, o texto de referência é Die Stadt der träumenden Bücher) e que são publicados no livro em nome do autor ou com seu consentimento (Id., 1992).

${ }^{4}$ Como desdobramentos da ficção autoral após a publicação desse romance pode-se apontar uma manifestação recente do escritor, que tenta, por mais uma vez, reforçar o seu papel de mero tradutor. Na Frankfurter Buchmesse de 2011 foi lançado seu último romance: Das Labyrinth der träumenden Bücher, no qual Mythenmetz retorna a Buchhaim. Walter Moers não compareceu à feira de livros na tarde de autógrafos, porém seu editor estava presente carimbando os livros do público com a assinatura do autor, ou seja, de Hildegunst von Mythenmetz. Cf. <http://www.youtube.com/watch?v=-k--zodf5SA> $(09 / 03 / 2014)$
} 
Prado, L. A. - Fantasia e metaficcionalidade nos romances de Zamonien

e Mythenmetz, publicada no jornal Frankfurter Allgemeine Zeitung ${ }^{5}$, na qual "autor" e "tradutor" discutem quão fidedigna foi a tradução feita por Moers. Um segundo exemplo é o vídeo produzido por Achim Zeilmann e exibido na série aspekte da emissora $Z D F^{6}$, no qual o jornalista entrevista pessoalmente Mythenmetz (representado por um boneco em tamanho humano), que faz uma aparição pública e fala de sua obra, da tradução e dos problemas que teve com seu "tradutor" do idioma de Zamonien; manifesta-se, inclusive, sobre seu posicionamento frente à literatura contemporânea alemã. O programa foi exibido em 2007 e Walter Moers assinou o roteiro do vídeo.

Apesar dessas curiosas manifestações reforçando a não identidade entre Moers e Mythenmetz, a ficção autoral é insustentável, quando se trata, por exemplo, da capa do livro e da lombada do romance (peritexto), ou então, do próprio catálogo da editora, nos quais Walter Moers aparece de fato como autor. A ficção autoral é, todavia, proposta pelo escritor e encarada pelos leitores como um jogo. Espera-se do leitor implícito que ele aceite esse jogo, estabelecendo-se assim, um pacto lúdico entre o leitor e o texto (o pacto ficcional), que precisa acontecer para que o leitor prossiga com sua leitura. Nas palavras de Umberto ECO (2009: 81):

A norma básica para se lidar com uma obra de ficção é a seguinte: o leitor precisa aceitar tacitamente um acordo ficcional [...] O leitor tem que saber que o que está sendo narrado é uma história imaginária, mas nem por isso deve pensar que o escritor está contando mentiras. [...] Aceitamos o acordo ficcional e fingimos que o que é narrado de fato aconteceu.

Os leitores de Die Stadt der träumenden Bücher devem, portanto, aceitar o pacto ficcional proposto pelo autor e supor que Mythenmetz é o legítimo autor da obra, a qual deixa de ser um romance de fantasia e passa a ser a autobiografia desse grande escritor vindo de um continente desconhecido por nós.

\footnotetext{
${ }^{5}$ Platthaus, Andreas. Andreas Platthaus im Gespräch mit Walter Moers. „Natürlich bleibt Ihr Buch ein Schmarrn“. Frankfurter Allgemeine Zeitung, Frankfurt, 04.10.2007. Disponível em:

$<$ http://www.faz.net/aktuell/feuilleton/buecher/moers-trifft-mythenmetz-natuerlich-bleibt-ihr-bucheinschmarrn-1488651.html> (09/03/2014).

${ }^{6}$ Parte 1 disponível em: <http://www.youtube.com/watch?v=E3JwEVYcGBk>; Parte 2 disponível em: $<$ http://www.youtube.com/watch?v=I9-eLrAxErw > (09/03/2014)
} 
Prado, L. A. - Fantasia e metaficcionalidade nos romances de Zamonien

\section{A Fantasy de Walter Moers ${ }^{7}$}

Nas estantes de livrarias alemãs ou mesmo em sites de compras na internet como a Amazon, os romances de Zamonien são normalmente encontrados das seções de Fantasy e Science Fiction ou Jugendliteratur ${ }^{8}$.

PesCH (2009: 6) define o gênero da Fantasy em poucas, mas elucidativas palavras: "Fantasy - das sind Geschichten von Zauberern und Helden, Drachen, Elfen und Zwergen, von magischen Ringen und verborgenen Schätzen, versunkenen Kulturen, erfundenen Welten und privaten Mythologien [...]”. Há nessas histórias, nas quais o maravilhoso e o sobrenatural prevalecem sem que haja um efeito de estranhamento no leitor ou mesmo em um dos personagens (cf. TODOROV 2008), algumas convenções com relação à estrutura narrativa e às temáticas recorrentes. Trataremos a seguir dessas questões com o intuito de esboçar as características do gênero recorrendo a exemplos encontrados em Die Stadt der träumenden Bücher.

Pensemos primeiramente do enredo do romance: Mythenmetz é um jovem que recebe uma missão importante. Para cumprir essa missão, ele terá que iniciar uma dura jornada que o levará a percorrer longas distâncias, fazer amigos e inimigos, viver aventuras, mas também a enfrentar muitos perigos e árduas batalhas contra o mal. Identificam-se nessa breve descrição do plot alguns elementos temáticos típicos da Fantasy: uma jornada, um protagonista-herói, um antagonista representante do mal e uma disputa que pode ser fatal para qualquer um dos lados envolvidos.

PESCH (2009: 168) vê na temática da jornada um princípio de organização recorrente nesse tipo de narrativa fantástica. Partindo do esquema cíclico de Campbell (1949, apud PESCH 2009: 45), identificam-se na quest três momentos distintos: a partida, a iniciação e o retorno. Isso significa que o herói será primeiramente confrontado, de

\footnotetext{
${ }^{7}$ Optamos por utilizar o termo em língua inglesa Fantasy para designar o gênero literário com o qual se ocupa esta pesquisa, de acordo com a terminologia adotada pela crítica literária alemã, assim como pela crítica anglófona e francófona, que vincula o termo fortemente à literatura na tradição de J.R.R.Tolkien e outros autores, cuja proposta literária se assemelhe a esta (Cf. PESCH 2009). Na língua portuguesa ainda há certa confusão terminológica ao se lidar com esse tipo de literatura. Fala-se de literatura fantástica ou de romance de fantasia, sem que haja uma especificação ao gênero da Fantasy.

${ }^{8} \mathrm{Cf}$.<http://www.amazon.de/s/ref=nb_sb_noss_1?_mk_de_DE=\%C3\%85M\%C3\%85\%C5\%BD $\% \mathrm{C} 3 \% 9$ $5 \% \mathrm{C} 3 \% 91 \&$ url=node $\% 3 \mathrm{D} 142 \&$ field-

keywords=walter+moers+zamonien $\& \mathrm{rh}=\mathrm{n} \% 3 \mathrm{~A} 186606 \% 2 \mathrm{Cn} \% 3 \mathrm{~A} 142 \% 2 \mathrm{Ck} \% 3$ Awalter+moers+zamonie $n>(09 / 03 / 2014)$
} 
Prado, L. A. - Fantasia e metaficcionalidade nos romances de Zamonien

maneira inesperada, com uma missão. Essa missão exigirá dele que abandone sua vida e seu universo particular para que saia em uma jornada, normalmente longa e por territórios distantes e desconhecidos. Durante sua jornada, o herói irá enfrentar diversos desafios, porém contará com auxílio e com a proteção de personagens que surgirão em seu caminho. Depois de se deparar com os mais inusitados imprevistos, o herói há de superar as adversidades e cumprir sua missão. Satisfeito e recompensado por todos seus feitos, ele volta mais amadurecido e, de certa forma, modificado ao seu universo inicial.

A quest apresenta, portanto, um movimento cíclico iniciado com a partida e finalizado com o retorno do herói. O objetivo de sua jornada é, em primeira instância, coletivo. O herói há de cumprir sua missão por um bem maior de um povo ou até mesmo de todo o mundo. No entanto, há também um objetivo centrado no indivíduo, pois as provações, às quais ele será submetido farão com que ele próprio se modifique (cf. PESCH 2009: 169).

O "final feliz" da Fantasy é, como se pode ver, previsto e esperado pelo leitor. Não caberia no esquema narrativo que o personagem principal eventualmente falhe em sua missão ou que ele sucumba e morra em um de seus desafios mortais. J. R. R. TOLKIEN (2006: 77), cujas obras acabaram por se tornar o modelo de romance para o gênero, afirma que o final feliz não só é constitutivo da Fantasy, como também é indicador da qualidade literária da obra:

[...] O sinal de uma boa história de fadas, do tipo mais elevado ou mais completo, é que, não importa quão desvairados sejam seus eventos, quão fantásticas ou terríveis as aventuras, ela pode proporcionar à criança ou ao adulto que a escuta, quando chega a "virada", uma suspensão de fôlego, um batimento e ânimo no coração, próximos às lágrimas (ou de fato acompanhados por elas), tão penetrantes como aqueles dados por qualquer forma de arte literária, e com uma qualidade peculiar.

No modelo esquemático da quest, comumente o protagonista da narrativa parte em busca de algo valioso ou simbólico. Esse "algo" remete quase sempre a um objeto real, como um anel, um tesouro; ou então, a algo simbólico e abstrato, como o bem da humanidade, a salvação do mundo ou o amor. Todavia, no caso da jornada de Mythenmetz, esse quadro inverte-se na narrativa: o protagonista já tem o objeto valoroso em suas mãos - o manuscrito - procurando então, o escritor que concebeu aquela obra. Durante a jornada forma-se outro escritor, o próprio protagonista. Essa 
Prado, L. A. - Fantasia e metaficcionalidade nos romances de Zamonien

quest transforma-se, por sua vez, em um processo de formação, cujo final o leitor já conhece, pois o próprio Mythenmetz apresenta-se como escritor do livro e autor consagrado (cf. HANUSCHEK 2011: 50-51).

No entanto, a jornada de Mythenmetz não completa o movimento cíclico com o retorno a sua terra natal. É possível supor que o protagonista retorne a Lindwurmfeste e que lá ele escreva o seu grande romance, porém essa ação não se realiza durante a narrativa, que se encerra com a fuga de Mythenmetz da cidade de Buchhaim enquanto esta é consumida pelo fogo causado após uma grande disputa com "Phistomefel Smeik", o grande antagonista da narrativa.

"Phistomefel Smeik" é o livreiro mais poderoso de Buchhaim, que secretamente manipula e administra todo o mercado editorial de Zamonien. É ele quem define o que é boa ou má literatura, o que será vendido ou não, qual escritor receberá destaque e qual será completamente esquecido pelo público. É inevitável associar a figura de "Phistomefel Smeik" a uma outra figura da literatura alemã que representa o mal ardiloso, Mephistofeles. Isso devido ao anagrama a partir do qual foi criado o nome do personagem (cf. FESLER 2008: 61-62). O antagonismo entre Smeik e Mythenmetz se dá por causa do manuscrito que o Lindwurm tem em mãos. Sua qualidade literária é tão grande que seria capaz de destruir todo o mercado literário que Smeik comanda.

Dentro desse contexto, MatTenKLotT (2003: 48) identifica um segundo motivo central da Fantasy: a eterna luta entre o bem e o mal: "Das Böse erscheint dabei oft [...] als allgegenwärtig drohende, schwer zu fassende, gesichtslose Macht. Es wird als gewaltige Übermacht gezeichnet, denn wenn es sich auch in einer Person konzentriert, so verfügt es doch über unzählige ergebene Helfershelfer.”. No romance de Walter Moers, essa figura representativa do mal surge inicialmente no personagem "Schattenkönig", um monstro que habita as catacumbas de Buchhaim, um labirinto infinito de estantes de livros. No desenvolver da trama elucida-se que essa interpretação inicial é errônea e que Phistomefel Smeik é de fato o personagem maléfico da narrativa

\footnotetext{
9 Personagem de grande importância para a narrativa. O leitor descobre no final do romance que Schattenkönig é o autor do aclamado manuscrito. Ele foi um dia humano, um escritor muito talentoso que partiu para Buchhaim na intenção de publicar seu manuscrito. No entanto, Smeik decidiu bani-lo da cidade, transformando-o em um monstro: uma criatura feita a partir de livros e órgãos de outros seres, que deveria viver nos labirintos de livros que constituem as catacumbas de Buchhaim.
} 
Prado, L. A. - Fantasia e metaficcionalidade nos romances de Zamonien

e estabelece seu antagonismo não só com relação ao protagonista Mythenmetz, como também a Schattenkönig.

Tratemos agora do cenário no qual a história de Mythenmetz se passa. Um continente fictício denominado "Zamonien" é o palco de todas as aventuras vividas pelo protagonista. Nesse universo vivem seres completamente desconhecidos para nós, leitores: "Lindwürme", "Bücherjäger", "Buchlinge”, “Lebende Zeitungen", "Fhernhachenzwerge", "Eydeete", "Haifischmaden", "Schweinsäugleine", entre tantos outros. Completam esse cenário uma fortaleza de dragões escritores, uma cidade feita de livros, labirintos subterrâneos que mais se assemelham a uma biblioteca infinita, laboratórios para experimentos dos "Buchimisten", um castelo habitado por sombras e livros que estão vivos e sonham com o dia em que serão lidos. Em Zamonien fala-se "zamonisch", um idioma do qual não há registros no mundo "real" do leitor. Lá regem outras leis, que não as nossas.

Walter Moers cria em Zamonien um "Anderswelt", um mundo completo e complexo, inventado pelo autor em seus mínimos detalhes. Tudo nesse universo bastante característico da Fantasy pode ser criado, contanto que a construção do espaço ficcional seja lógica, consistente, coerente e coesa (cf. SOLMS 1994: 20).

Naturalmente nem tudo é criado exclusivamente pelo autor, pois muito do universo ficcional é construído a partir daquilo que já é conhecido como algo elementar da vida: a mudança das estações, o tempo, os fenômenos naturais, a necessidade das personagens dormirem e se alimentarem, etc. Grande parte do cenário inventado é, inclusive, parte do mundo real, como flores, pedras, montanhas, colinas, cavernas, campos, cidades, etc. (cf. FESLER 2008: 10-11).

Quando o leitor é introduzido no "Anderswelt", há inicialmente uma quebra da continuidade espacial, uma vez que se trata de outro mundo bastante diferente daquele com o qual o leitor está familiarizado. Ao mesmo tempo, é interrompida a continuidade temporal, remetendo-se frequentemente a um passado longínquo e também desconhecido pelo leitor, de maneira que se faz necessário preenchê-lo com informações da nova realidade ficcional. A retomada do passado aponta para tempos pré-industriais, eventualmente medievais, quando a natureza ainda era intocada por homens e regida por forças maiores, muitas vezes míticas (ibd.: 11). 
Prado, L. A. - Fantasia e metaficcionalidade nos romances de Zamonien

Em Die Stadt der träumenden Bücher não há datação específica, mas estão implícitos tempos passados, pois os personagens locomovem-se através de animais, quando não a pé; a vida cotidiana dos habitantes de Zamonien acontece sem grande uso de tecnologia; as figuras secundárias vivem de trabalhos manuais, agricultura ou arte; e quando há cenas de luta, os personagens estão munidos frequentemente apenas de suas mãos ou então, de aparatos muito simples e antiquados (cf. FESLER 2008: 42).

Um suporte textual bastante utilizado na Fantasy para sustentar a referência temporal a um momento histórico passado é o estilo linguístico adotado pelo autor. Frequentemente são utilizadas formas linguísticas elevadas, arcaicas e pouco usuais, que por um lado causam estranhamento ao leitor, mas, por outro, aproximam-no do universo fictício. Walter Moers, no entanto, não faz uso desse recurso em nenhum de seus romances. Pelo contrário, o autor preza por um uso atual, irreverente e informal da língua alemã. Expressões e gírias modernas e atuais são encontradas a cada página de suas obras, tanto em diálogos entre personagens, como em descrições de cenário (cf. FESLER 2008: 94). Um pequeno exemplo do registro coloquial bastante atual utilizado por Moers pode ser lido no trecho a seguir, quando Mythenmetz está prestes a receber o misterioso manuscrito no leito de morte de seu padrinho literário:

[...] Ich muss es hier gestehen, dachte ich etwas Unerhörtes. Denn was mir im nächsten Augenblick durch den Kopf ging, war im exakten Wortlaut: "Hoffentlich kratzt er jetzt nicht ab, bevor er mir erzählt hat, was in diesem verdammten Brief stand."

Nein, ich dachte nicht "Hoffentlich stirbt er nicht" oder "du musst leben, Dichtpate!" oder so etwas ähnliches, sondern obenstehenden Satz, und ich schäme mich bis auf den heutigen Tag, dass darin das Wort "abkratzen" vorkam. (MOERS 2008:18)

Sua forma de lidar com a língua alemã mostra-se tanto mais criativa e irreverente ao se analisar os neologismos e as brincadeiras que o autor faz com palavras e seus significados para nomear personagens, espécies de habitantes de Zamonien, assim como cenários do continente. Tomem-se, como exemplo, os termos utilizados em alemão para designar pessoas ávidas por leitura: "Bücherwürmer" e "Leseratten". Estes não indicam personagens que encontram prazer no ato da leitura, mas sim, figuras reais encontradas nas catacumbas da cidade dos livros e que representam um perigo genuíno aos passantes desavisados (cf. FESLER 2008: 37). 
Prado, L. A. - Fantasia e metaficcionalidade nos romances de Zamonien

O processo de composição de palavras, ao qual Moers recorre para denominar personagens é tematizado diversas vezes em seus romances. Um exemplo é um dos monstros retratados nas catacumbas de Buchhaim: a "Spinxxxxe", uma aranha gigante que possui dezesseis patas. Em uma nota de rodapé, encontra-se um comentário a respeito da ortografia do termo na língua alemã, feita pelo suposto tradutor do romance, no caso Walter Moers (MoERs 2008: 190):

Im Zamonischen Alphabet gibt es einen Buchstaben, der Vielbeinigkeit symbolisiert und der in jedem Namen einer Daseinsform vorkommt, die über mehr als acht Beine verfügt. Ein solcher Buchstabe fehlt in unserem Alphabet, daher mußte ich mir mit der vielfachen Verwendung des Buchstaben $\mathrm{X}$ behelfen, die meiner Meinung nach recht schön Sechzehnbeinigkeit symbolisiert. Das heißt aber nicht, daß man alle vier $X$ aussprechen muß. Sprechen Sie den Namen der Spinxxxxe einfach so aus, als hätte er nur ein $X$.

O registro coloquial da linguagem nos romances de Moers, a informalidade de sua escrita, assim como a criação de neologismos, ou mesmo a atribuição de novo sentido a termos da língua alemã já conhecidos pelo leitor servem inicialmente de suporte ao caráter humorístico e satírico de seus textos, marca registrada do autor desde a publicação de seus primeiros quadrinhos. Embora o humor e a sátira distanciem seus romances das convenções da Fantasy, na qual o tom sério geralmente prevalece, esses elementos ressaltam a originalidade e o potencial criativo de Walter Moers.

Nota-se também que o humor em Die Stadt der träumenden Bücher é construído principalmente a partir de referências encontradas na diegese ao nosso mundo real. Diferente de muitas obras da Fantasy, nas quais o "Anderswelt" apresenta-se como um universo distante, inacessível e até mesmo como um cenário já extinto do mundo que conhecemos, Zamonien é bastante próxima do leitor: um continente dentro de um mundo que não é tão diferente do nosso, até mesmo se compararmos os mapas desse universo fictício com o nosso mapa-múndi "real" "10. Um continente no qual podemos

\footnotetext{
${ }^{10}$ A topografia de Zamonien é documentada visualmente através de doze mapas, divididos nos romances de Moers. No primeiro romance, Die 13 1/2Leben des Käpt'n Blaubär (MOERS 2002: 10-11), encontra-se uma representação continente fictício: "Zamonien und seine weitere Umgebung". De acordo com o mapa pode-se ver Zamonien representada em um mapa-múndi, o que indica ao leitor que este continente faz parte do mesmo planeta que ele habita. Nesse mapa estão ilustrados continentes inteiramente fictícios ("Ü”, "Unland", "Mumien", "Yhôll”, "Nafklathu”, "Perm", "Urien”, “Go", "Zamonien”), continentes reais (Amerika, Südamerika, Afrika, Asien, Australien) e algumas ilhas, cujos nomes podem ser associados a reais "Kalt"/Ártico, "Eisland"/Antártida,
} 
Prado, L. A. - Fantasia e metaficcionalidade nos romances de Zamonien

reconhecer hábitos, instituições, personalidades, ciências, artes e também escritores consagrados da literatura mundial que conhecemos da nossa própria realidade.

É nesse ponto que chegamos ao aspecto mais inovador da Fantasy de Walter Moers: o jogo com a ficcionalidade a partir de elementos metaficcionais.

\section{humor a partir do jogo com a ficcionalidade}

A temática da literatura e da escrita literária, de escritores e leitores, tão recorrente na literatura pós-moderna também se faz notar na Fantasy, seja ela voltada para o público jovem ou adulto. Walter Moers e seus romances de Zamonien são um exemplo bastante claro desse fenômeno.

Uma vez que Die Stadt der träumenden Bücher tem a literatura como eixo temático central, é inevitável que se estabeleçam relações intertextuais com outras obras literárias. Da mesma maneira, identifica-se uma clara referência à literatura, à escrita literária e ao próprio texto que o leitor tem em mãos. Trata-se de uma literatura que tematiza a própria literatura, ou seja, uma metaficção.

Segundo BÖHN (2010: 11), textos ficcionais e não ficcionais tem algo em comum: ambos se referem a fatos e acontecimentos, ou seja, a algo do mundo. A diferença entre ficção e não ficção consistiria, principalmente, nas exigências com relação ao caráter de verdade das asserções feitas pelo escritor de uma obra. Em contrapartida, a metaficção não se refere exclusivamente ao mundo, e sim, ao próprio texto e às características da ficcionalidade. $\mathrm{O}$ principal elemento constitutivo de obras metaficcionais é, portanto, a autorreferencialidade. Em outras palavras, a literatura fala de si mesma.

Muitos são os exemplos que apontam para o caráter metaficcional de Die Stadt der träumenden Bücher: a composição dos nomes das personagens, digressões do protagonista que tratam de gêneros literários e da escrita de romances, referências a lugares fictícios de outras obras literárias, paralelos com personagens consagradas da

“Grünland”/Groenlândia,"Kleintroll”/Islândia, "Großtroll”/Escandinávia). O continente de Zamonien é, dessa forma, integrado em um mundo que não nos é de todo desconhecido (Cf. LEMBKE 2011: 91-93). 
Prado, L. A. - Fantasia e metaficcionalidade nos romances de Zamonien

literatura mundial, anagramas a partir de nomes de escritores consagrados, referências ou citações diretas a obras clássicas da literatura mundial, assim como paródias das mesmas, entre outros. Tratarei brevemente desses aspectos apresentando alguns exemplos tirados desse romance, a começar pelos nomes dos personagens.

Existem algumas figuras que apresentam já na composição de seus nomes uma referência direta à literatura e à escrita literária. É o caso de Hildegunst von Mythenmetz. A palavra "Mythenmetz" é um composto a partir de "Mythen" e "Steinmetz". Atribui-se ao escritor, no caso, o protagonista, a função de talhar os mitos de forma artesanal, de construir de maneira quase que manual as suas palavras e ideias em narrativas. O mesmo se dá com o nome do padrinho literário de Mythenmetz “Danzelot von Silbendrechsler". O nome do personagem é composto a partir dos termos "Silben" e "Drechsler" que também associam o trabalho da escrita literária à arte artesanal (cf. LEMBKE 2011: 23).

Em diversos momentos da história, Mythenmetz, um escritor em formação, tece comentários a respeito de diferentes gêneros literários ou então, de certas correntes e tendências literárias. É o que acontece, por exemplo, em determinado momento da narrativa, no qual Mythenmetz chega ao "Schloss Schattenhall" - a reclusa e assustadora moradia do "Schattenkönig". O personagem encontra-se do lado de fora do castelo e reflete sobre a situação em que se encontra. Ele reconhece então, elementos narrativos característicos da literatura trivial (na obra descrita como "Schauerliteratur") e resolve comportar-se de maneira mais esperta do que as personagens de tais narrativas fariam:

Es gibt etliche Werke der Zamonischen Schauerliteratur, in denen der Held in eine ähnliche Situation gerät. Eine Situation, in der man als Leser am liebsten das Buch anschreien möchte: "Geh nicht! Geh da bloß nicht rein, du Idiot! Das ist eine Falle!" Aber dann läßt man das Buch sinken, lehnt sich zurück und denkt: "He - wieso eigentlich nicht? Soll er doch reingehen! Da drinnen lauert bestimmt eine hundertbeinige Riesenspinne, die ihn in einen Kokon einwickeln will oder so was - das wird bestimmt lustig. Das ist schließlich ein Held der Zamonischen Schauerliteratur, der muß das aushalten können". Und er geht natürlich rein, der Held der Zamonischen Schauerliteratur, gegen jede Vernunft, und prompt wird er von einer hundertbeinigen Riesenspinne in einen Kokon entwickelt oder so was. Aber nicht mit mir! Ich würde nicht hineingehen. Ich war gebrannt und fallengeprüft durch schmerzliche Erfahrung, ich war kein stupider Held, der zur Befriedigung niedriger Unterhaltungsbedürfnisse sein Leben riskierte! Nein, ich würde nicht wirklich hineingehen - ich würde nur ein bißchen hineingehen. Denn was konnte daran schon verkehrt sein? [...] (MOERS 2008: 324) 
Prado, L. A. - Fantasia e metaficcionalidade nos romances de Zamonien

O personagem-narrador acaba por se comportar como qualquer outro protagonista desse tipo de literatura esquemática e trivial, o que traz um efeito cômico aos comentários irônicos a respeito da "Schauerliteratur".

Die Stadt der träumenden Bücher apresenta três cenários diferentes para o desenrolar do enredo: a "Lindwurmfeste", local de nascimento de Mythenmetz, onde todos os habitantes se dedicam à literatura e às questões estéticas, sem se preocupar com questões práticas e cotidianas e nem mesmo com o mercado editorial; a cidade de "Buchhaim", onde todo o mercado literário está em efervescência, e, por fim, as catacumbas de "Buchhaim", uma biblioteca subterrânea infindável, onde os maiores tesouros da literatura de Zamonien podem ser encontrados. É nesse último lugar que se passa a maior parte do romance.

A partir desses três diferentes cenários, identificamos referências intertextuais a outras obras da literatura fantástica: a Lindwurmfeste assemelha-s à torre de Marfim em Unendliche Geschichte (1979), de Michael Ende. Um local recluso, onde reside a Imperatriz-Menina e o único lugar em Fantasia que ainda está protegido e preservado do Nada que assola o reino. As inúmeras livrarias e bibliotecas de Buchhaim, assim como os corredores infindáveis repletos de estantes de livros nas catacumbas subterrâneas da cidade remetem imediatamente à simbólica Biblioteca de Babel (1944), de Jorge Luis Borges, ou mesmo à misteriosa biblioteca do mosteiro beneditino representada em $O$ nome da Rosa (1980), de Umberto Eco (Cf. GoslaR 2011).

Outros exemplos de referência intertextual podem ser encontrados na clara menção a personagens literários conhecidos de outras obras. É o caso, por exemplo, da relação entre Phistomefel Smeik e Mephistofeles, como mencionado anteriormente. Tal paralelo pode também ser estabelecido entre a figura de Schattenkönig e o monstro de Frankenstein do romance de Mary Shelley. Ambos são criaturas concebidas em um laboratório e escorraçadas por seus criadores. Ambos os monstros ressentem-se, são vistos como criaturas abjetas e, por fim, procuram a vingança, causando sofrimento a seus respectivos criadores (cf. SCHÄBLER 2011).

É, no entanto, em um tipo de criatura de Zamonien que podem ser encontrados os maiores exemplos de intertextualidade e de manifestação da metaficcionalidade em Die Stadt der träumenden Bücher, os "Buchlinge". Estas são criaturas parecidas com ciclopes, que vivem no subterrâneo de Buchhaim e que sobrevivem da literatura. Para 
Prado, L. A. - Fantasia e metaficcionalidade nos romances de Zamonien

eles, tudo gira em torno de livros e leituras, de maneira que até sua alimentação é realizada por meio da leitura. Cada uma dessas criaturas é batizada com o nome de um escritor de Zamonien e, a partir desse momento, ele deverá dedicar sua vida ao estudo e à memorização das obras desse escritor ${ }^{11}$.

Ao nos depararmos com alguns nomes desses personagens, podemos reconhecer anagramas formados a partir de nomes de escritores mundialmente conhecidos: "Ojahnn Golgo van Fontheweg” (Johann Wolfgang von Goethe), "Gofid Letterkerl” (Gottfried Keller), "Perla La Gadeon” (Edgar Allan Poe), “Ali Aria Ejmirrner” (Rainer Maria Rilke), "Eseila Wimpershlaak" (William Shakespeare), entre outros ${ }^{12}$.

Esses personagens são, na maioria das vezes, apresentados ao leitor juntamente com uma citação de alguma de suas obras e, não raro, seguem-se comentários pessoais do narrador com relação a esses escritores. É o caso do Buchling “Ojahnn Golgo van Fontheweg", quando este se apresenta a Mythenmetz e recita alguns versos de sua obra mais conhecida:

$[\ldots]$

\section{"Die Frage scheint mir klein}

Für einen, der das Wort so sehr verachtet, Der, weit entfernt von allem Schein,

Nur in der Wesen Tiefe trachtet. «

Ich versuchte die Ansprache des Gnoms zu deuten. [...]»Wie meinst du das? « fragte ich. »Sag doch einfach, wer du bist! « Er wagte sich noch weiter aus seiner Deckung hervor.

» Ich bin ein Teil des Teils, der anfangs alles war,

Ein Teil der Finsternis, die sich das Licht gebar.«

Wieso kam mir das so bekannt vor? Moment mal! Das war ein Zitat! Ein Zitat von... von...

»Das war ein Zitat von Ojahnn Golgo van Fontheweg «, rief ich. Klar war das Fontheweg - dieser unerträgliche Platzhirsch der Zamonischen Klassik. Der Liebling aller Kritiker und der Schrecken aller Schulkinder. Das war eine Stelle aus Weisenstein, seinem bekanntesten Buch. [...]

$[\ldots]$

»So ist es. Das ist mein Name.«

»Dein Name? Du bist Ojahnn Golgo van Fontheweg? « »Jawohl. Du kannst mich Golgo nennen, das tun alle!«

\footnotetext{
${ }^{11}$ Podemos traçar aqui também um paralelo com personagens da ficção científica Fahrenheit 451, de Ray Bradbury, os quais preservam as grandes obras literárias gravadas em suas mentes.

${ }^{12}$ A lista completa dos anagramas que surgem no romance, assim como o nome equivalente dos escritores pode ser encontrada em < http://www.mythenmetz.de/zamonische_dichter.php> (09/03/2014)
} 
Prado, L. A. - Fantasia e metaficcionalidade nos romances de Zamonien

Ich war verwirrt. Fontheweg war seit neunhundert Jahren tot. ${ }^{13}$

(MOERS 2008: 210-211)

Os trechos citados ipsis litteris pelo "Buchling" são versos da cena "Quarto de Trabalho", da tragédia Faust, de Goethe, na qual Mefisto apresenta-se a Fausto e lhe propõe e aposta (GoETHE 2004: 136-140). Fausto, no entanto, se chama em Zamonien "Weisenstein" e Goethe, “Golgo". Golgo é, no continente de fictício de Zamonien, “der Lieblieng aller Kritiker umd der Schrecken aller Schulkinder”, o que talvez não se distancie tanto da figura do próprio Goethe em nosso mundo real.

Há também exemplos de citações que modificam o texto original, como em uma cena, na qual Ojahnn Golgo van Fontheweg declama um poema intitulado "Der Nurnenwald", que remete imediatamente a Ein Gleiches, de Goethe ${ }^{14}$ :

Der Nurnenwald
Über allen Gipfeln
Ist Ruh,
In allen Wipfeln
Spürest du
Kaum einen Hauch
Die Nurnen schweigen im Walde
Warte nur, balde
Ruhest du auch

\section{Ein Gleiches}

Über allen Gipfeln

Ist Ruh, In allen Wipfeln

Spürest du

Kaum einen Hauch;

Die Vögelein schweigen im Walde.

Warte nur, balde

Ruhest du auch.

Há apenas uma pequena modificação na citação feita no romance de Walter Moers, que consiste na alteração do termo "Vögelein" por "Nurnen", seres fictícios que se assemelham à madeira e que possuem oito patas. Essa é a forma encontrada pelo autor de "zamonizar" um poema tão conhecido na literatura alemã, para que ele possa ser inserido de maneira coerente no universo fictício de Zamonien (cf. GOSLAR 2011: 270). Nesse continente não há passarinhos voando e sim, "Nurnen”, seres estranhos, porém cabíveis a esse universo. A substituição dessa única palavra traz o leitor que começava a

\footnotetext{
${ }^{13}$ Grifos nossos.

${ }^{14}$ Grifos nossos. Disponível em: $<$ http://www.zeno.org/Literatur/M/Goethe,+Johann+Wolfgang/Gedichte/Gedichte+(Ausgabe+letzter+Ha nd.+1827)/Lieder/Ein+gleiches> (09/03/2014)
} 
Prado, L. A. - Fantasia e metaficcionalidade nos romances de Zamonien

relacionar o poema com algo conhecido por ele em sua realidade de volta para o mundo inventado por Walter Moers.

\section{Conclusão}

A partir desses exemplos pôde-se observar como Moers faz uso de recursos da intertextualidade e de elementos metaficcionais para estabelecer um jogo com a ficcionalidade e trazer humor para seus textos. Essa é a característica mais marcante de sua obra.

O jogo com a ficcionalidade vai além do texto, quando pensamos na ficção autoral criada por Moers no peritexto e em epitextos. Ao reiterar que não é autor de Die Stadt der träumenden Bücher e que um "Lindwurm" chamado Hildegunst von Mythenmetz é o autor legítimo dessas memórias, Moers faz uso de um recurso próprio da ficção: o de tratar algo inventado como se fosse real. Enquanto ele insiste em sua não autoria e na autobiografia de Mythenmetz, acaba por evocar todo o seu universo fictício, presentificando-o e expondo-o aos olhos dos leitores, de maneira que sua autoria seja apenas confirmada. Dessa maneira, ele acaba por chamar a atenção de seu leitor para o caráter de invenção de seu romance (cf. BUNIA 2010: 199)

Moers cita claramente suas fontes, ainda que elas estejam escondidas em anagramas ou em breves referências. Ao fazer uso desses recursos, ele convida seus leitores a participarem de um jogo de adivinha e a interagir com o texto. Se a intenção do autor é, por um lado, fazer uma brincadeira que leve seu leitor a abrir um sorriso ou até mesmo a dar risada, por outro lado, Moers também chama a atenção de seu leitor para o caráter de construção intertextual de seu romance, instigando-o a manter uma postura atenta a possíveis referências e associações do mundo inventado ao mundo real.

Walter Moers desconstrói textos amplamente conhecidos, para construí-los novamente em cima de uma nova base de significado. Dessa maneira, ele conduz seus leitores para que eles estabeleçam relações com tudo aquilo que já leram e com seus conhecimentos a respeito da literatura. As relações intertextuais são inúmeras, assim como as associações feitas pelos leitores a partir do confronto com essas referências. 
Prado, L. A. - Fantasia e metaficcionalidade nos romances de Zamonien

A leitura dos romances de Moers é uma leitura leve, divertida, dinâmica e bastante instigante. Além disso, muitas camadas de leitura - umas mais superficiais, outras mais profundas -, abrem-se para aquele leitor mais atento. A leitura de Die Stadt der träumenden Bücher não pressupõe que todas as referências intertextuais e os mecanismos metaficcionais sejam identificados pelo leitor para que o livro cumpra seu objetivo: entreter e transportar-nos a um mundo onde tudo é possível, inclusive acompanhar as aventuras de um dragão-escritor que se tornou amigo de Goethe e Keller, os quais ainda estão vivos em algum lugar nas catacumbas da Cidade dos Livros Sonhadores.

\section{Referências bibliográficas}

BöHN, Andreas. Metafiktionalität, Erinnerung und Medialität in Romanen von Michael Kleeberg, Thomas Lehr und Wolf Haas. In: BAREIS, A. / GRUB, F. T. (org). Metafiktion. Analysen zur deutschsprachigen Gegenwartsliteratur. Berlin: Kaleidogramme 57, 2010. $11-34$.

BunIA, Remigius. Mythenmetz \& Moers in der Stadt der Träumenden Bücher - Erfundenheit, Fiktion und Epitext. In: BAREIS, A. / GRUB, F. T. (org). Metafiktion. Analysen zur deutschsprachigen Gegenwartsliteratur. Berlin: Kaleidogramme 57, 2010. 189- 201.

CAMPBELl, Joseph. The Hero with a Thousand Faces, New York, 1949.

ECO, Umberto. Seis passeios pelo bosque da ficção. São Paulo: Companhia das Letras, 2006.

FESLER, Mario. Die Zamonien-Romane von Walter Moers als zeitgenössische Vertreter der Gattung Fantasy. Norderstedt, 2007.

GenetTe, Gerárd. Fiktion und Diktion. München: Wilhelm Fink, 1992.

GoETHE. Johann Wolfgang von. Fausto: Uma tragédia. São Paulo: Editora 34, 2004.

GosLAR, Tim-Florian. Zurück nach Arkadien. Die Kulturlandschaften Zamoniens in "Die Stadt der träumenden Bücher". In: Lemnke, Gerrit (org.).Walter Moers' Zamonien-Romane: Vermessungen eines fiktionalen Kontinents. Göttingen: V\&R unipress GmbH, 2011. 261-280.

HANUSCHEK, Sven. Die Antworten auf fast alle Fragen von heute stehen in alten Büchern. Trivialdramaturgie und ihre Rettung in Walter Moers' Zamonien-Romane. In: LEMKE, Gerrit (org.). Walter Moers' Zamonien-Romane: Vermessungen eines fiktionalen Kontinents. Göttingen: V\&R unipress GmbH, 2011. 45-58.

LEMBKE, Gerrit. "Hier fängt die Geschichte an". Moers' Zamonien-Romane. Vermessungen eines fiktionalen Kontinents. In: (org.). Walter Moers' Zamonien-Romane: Vermessungen eines fiktionalen Kontinents. Göttingen: V\&R Unipress GmbH, 2011. $15-41$.

MattenKLOTt, Gundel. Harry Potter - phantastische Kinderliteratur. Auf den Spuren eines globalen Erfolgs. In: Stimmen der Zeit, 221. Band, Freiburg 2003. 39-51. 
Prado, L. A. - Fantasia e metaficcionalidade nos romances de Zamonien

MOERS, Walter. Die 131/2 Leben des Käpt'n Blaubär. Die halben Lebenserinnerungen eines Seebären; mit zahlreichen Illustrationen und unter Benutzung des "Lexikons der erklärungsbedürftigen Wunder, Daseinsformen und Phänomene Zamoniens und Umgebung" von Prof. Dr. Abdul Nachtigaller. Frankfurt a. M.: Wilhelm Goldmann Verlag, 2002. [1999].

. Die Stadt der Träumenden Bücher. Ein Roman aus Zamonien von Hildegunst von Mythenmetz. Aus dem Zamonischen übertragen und illustriert von Walter Moers. München: Piper, 2008. [2004].

PESCH, Helmut W. Fantasy. Theorie und Geschichte einer literarischen Gattung. Köln: Eigenverlag, 2009. Disponível em http://www.helmutwpesch.de/downloads.htm> (09/03/2014)

SCHÄBLER, Daniel. Frankenstein und die Folgen. Zur Poetik des Monströsen bei Walter Moers. In: LEMNKE, Gerrit (org.).Walter Moers' Zamonien-Romane: Vermessungen eines fiktionalen Kontinents. Göttingen: V\&R unipress GmbH, 2011. 139-156.

SoLMS, Wilhelm. Einfach Phantastisch. Von der Wundererzählung zur phantastischen Literatur. In: LEBLANC, Thomas. SOLMS, Wilhelm (org.). Phantastische Welten.Märchen. Mythen Fantasy. Regensburg: Erich Röth Verlag, 1994. 9-22.

TODOROv, Tzvetan. Introdução à literatura fantástica. Perspectiva: São Paulo, 2008.

TOLKIEN, J.R.R. Sobre histórias de fadas. São Paulo: Conrad Editora do Brasil, 2006.

recebido em: 10/03/2014

aceito em:17/05/2014 